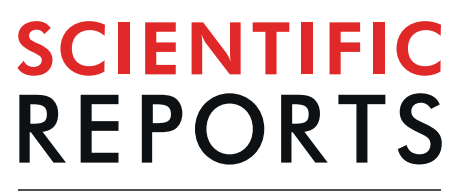

natureresearch

\title{
Impact of air pollution on breast cancer incidence and mortality: a nationwide analysis in South Korea
}

\author{
Jeongeun Hwang $\mathbb{D}^{1}$, Hyunjin Bae $\mathbb{1}^{1}$, Seunghyun $\mathrm{Choi}^{2}$, $\mathrm{Hahn} \mathrm{Yi}^{3}$, Beomseok Ko $\mathbb{i}^{4,6 *} \&$ \\ Namkug Kim $\mathbb{1}^{2,5,6 *}$
}

Breast cancer is one of the major female health problems worldwide. Although there is growing evidence indicating that air pollution increases the risk of breast cancer, there is still inconsistency among previous studies. Unlike the previous studies those had case-control or cohort study designs, we performed a nationwide, whole-population census study. In all 252 administrative districts in South Korea, the associations between ambient $\mathrm{NO}_{2}$ and particulate matter $10\left(\mathrm{PM}_{10}\right)$ concentration, and age-adjusted breast cancer mortality rate in females (from 2005 to 2016, $N_{\text {mortality }}=23,565$ ), and incidence rate (from 2004 to $2013, N_{\text {incidence }}=133,373$ ) were investigated via multivariable beta regression. Population density, altitude, rate of higher education, smoking rate, obesity rate, parity, unemployment rate, breastfeeding rate, oral contraceptive usage rate, and Gross Regional Domestic Product per capita were considered as potential confounders. Ambient air pollutant concentrations were positively and significantly associated with the breast cancer incidence rate: per $100 \mathrm{ppb} C \mathrm{O}$ increase, Odds Ratio OR $=1.08$ (95\% Confidence Interval $\mathrm{Cl}=1.06-1.10)$, per $10 \mathrm{ppb} \mathrm{NO}, \mathrm{OR}=1.14$ $(95 \% \mathrm{Cl}=1.12-1.16)$, per 1 ppb SO, OR $=1.04(95 \% \mathrm{Cl}=1.02-1.05)$, per $10 \mu \mathrm{g} / \mathrm{m}^{3} \mathrm{PM}_{10}, \mathrm{OR}=1.13(95 \%$ $\mathrm{Cl}=1.09-1.17)$. However, no significant association between the air pollutants and the breast cancer mortality rate was observed except for $\mathrm{PM}_{10}$ : per $10 \mu \mathrm{g} / \mathrm{m}^{3} \mathrm{PM}_{10}, \mathrm{OR}=1.05(95 \% \mathrm{Cl}=1.01-1.09)$.

Breast cancer is the most frequently diagnosed cancer among women worldwide ${ }^{1}$, and is rapidly increasing in industrialized countries and urban areas. In South Korea, breast cancer is the second most common after thyroid cancer and has annually increased by $6.1 \%$ from 1999 to $2014^{2,3}$. Increased exposure to environmental female hormones is considered to affect the rise of breast cancer incidence. In addition, hormone-dependent cancer is increasing in industrialized countries ${ }^{1,4}$.

There is growing evidence indicating that air pollution is a risk factor for breast cancer. Nitrogen oxides $\left(\mathrm{NO}_{2}\right.$ and $\left.\mathrm{NO}_{\mathrm{x}}\right)^{5-9}$, fine particulate matters $\left(\mathrm{PM}_{10} \text { and } \mathrm{PM}_{2.5}\right)^{10,11}$, and polycyclic aromatic hydrocarbons $(\mathrm{PAHs})^{12,13}$ are reported to associate with breast cancer incidence. The physiological mechanisms by which air pollutants affect breast cancer are largely explained in two ways. First, air pollutants may directly cause genetic mutations, as they are carcinogenic ${ }^{14,15}$. Second, air pollutants may affect breast cancer incidence by increasing breast density, which is known to be a risk factor. Yaghjyan et al. reported an association between exposure to $\mathrm{PM}_{2.5}, \mathrm{O}_{3}$, and mammographic breast density ${ }^{16}$. Female hormones affect breast density, and some air pollutants are known to exhibit endocrine-disrupting properties, including xenoestrogens ${ }^{17}$. However, in the Danish Diet, Cancer and Health cohort (1993-1997) study, little evidence of association between traffic-related air pollution exposure and breast density was found ${ }^{18}$. Hung et al. reported a positive association between high levels of $\mathrm{PM}_{2.5}$ and breast cancer mortality rate, by considering $\mathrm{PM}_{2.5}$ as a marker for polycyclic aromatic hydrocarbons ${ }^{19}$.

There is still an inconsistency among the evidence for the association between air pollution and breast cancer risk ${ }^{20}$. Though Crouse et al. ${ }^{6}$ found a positive association between $\mathrm{NO}_{2}$ concentration and the breast cancer incidence by $95 \%$ confidence, subsequent studies found positive associations with partial ${ }^{8,10,11}$, marginal

\footnotetext{
${ }^{1}$ Department of Medicine, University of Ulsan College of Medicine, Seoul, Republic of Korea. ${ }^{2}$ Department of Convergence Medicine, University of Ulsan College of Medicine, Asan Medical Center, Seoul, Republic of Korea. ${ }^{3}$ Asan Institute for Life Sciences, Asan Medical Center, Seoul, Republic of Korea. ${ }^{4}$ Department of Breast Surgery, University of Ulsan College of Medicine, Asan Medical Center, Seoul, Republic of Korea. ${ }^{5}$ Department of Radiology and Research Institute of Radiology, University of Ulsan College of Medicine, Asan Medical Center, Seoul, Republic of Korea. ${ }^{6}$ These authors contributed equally: Beomseok Ko and Namkug Kim. *email: spdoctorko@gmail.com; namkugkim@gmail.com
} 
or null $8,10,11,21-23$ statistical confidence. For example, Hystad et al. found a significant association between $\mathrm{NO}_{2}$ concentration and premenopausal breast cancer while marginal association were found between $\mathrm{NO}_{2}$ and postmenopausal breast cancer in Canadian women ${ }^{8}$. Conversely, Anderson et al. found significant positive associations between the incidence of postmenopausal breast cancer in European women and $\mathrm{NO}_{\mathrm{x}}$, and nickel in $\mathrm{PM}_{10}$, but found only suggestive evidence with $\mathrm{PM}_{2.5}, \mathrm{PM}_{10}, \mathrm{PM}_{\text {coarse }}, \mathrm{NO}_{2}$, and nickel in $\mathrm{PM}_{2.5}$, vanadium in $\mathrm{PM}_{2.5}$, and vanadium in $\mathrm{PM}_{10}{ }^{10}$. Incorporating more cases or expanding the cohort population may clarify the evidence, though such efforts would demand resources. There also were ecological studies on the association between breast cancer and air pollution ${ }^{5,7,9}$. Chen et al. ${ }^{5}$ and Wei et al. ${ }^{9}$ aggregated air pollutant emission data and age-adjusted breast cancer incidence rates in Surveillance, Epidemiology, and End Results Program of the United States National Cancer Institute that covered 199 counties and approximately 100,000 or less female population and found positive correlations. Datzman et al. ${ }^{7}$ found significant positive associations between $\mathrm{NO}_{2}, \mathrm{PM}_{10}$, and breast cancer incidence by using healthcare data from a local insurance corporation in Germany that covers approximately 1,000,000 female population and 9,577 incidences.

We performed an ecological study to investigate the associations between $\mathrm{CO}, \mathrm{NO}_{2}, \mathrm{SO}_{2}, \mathrm{O}_{3}, \mathrm{PM}_{10}$, and breast cancer incidence and mortality rate, in the whole of the 252 administrative districts in South Korea. South Korea has a unique national healthcare insurance system with the full coverage of its 52 million citizens and provides mammography-based breast cancer screening service for all female citizens with age $\geq 40$ in every two-years ${ }^{24}$. The lifetime screening rate for breast cancer in females with age $\geq 40$ was as high as $83.1 \%$ by $2013^{25}$. Among the Organization for Economic Co-operation and Development nations in 2012, South Korea have the eighth highest age-adjusted breast cancer incidence rate of 52.1 per 100,000, but have the lowest mortality rate of 6.1 per $100,000^{26}$. The full coverage of national healthcare insurance and the high screening rate may have facilitated appropriate medical intervention for breast cancer. The relative 5-year survival rate was higher than those of the United States and Japan in similar years: $92.3 \%$ in South Korea 2011-2015, 91.1\% in the United States 2007-2013, $91.1 \%$ in Japan 2006-2008, respectively ${ }^{26}$. Moreover, the national breast cancer screening service followed up all breast cancer patients in South Korea by residential address and exhaustively recorded the incidence and mortality rate ${ }^{24}$. These unique healthcare settings surrounding breast cancer make South Korea a natural testing ground to investigate associations between air pollution and breast cancer incidence and mortality rate.

\section{Results}

Characteristics of the observed districts throughout the study period are shown in Table 1. In Fig. 1, $\mathrm{NO}_{2}$ and $\mathrm{PM}_{10}$, concentrations and age-adjusted breast cancer incidence and mortality rates are portrayed on the South Korean map. Korean female population as of 2010 (in the middle of the study period) was $24,149,865$. The total number of breast cancer incidence in 2004-2013 was 133,373, and the total number of deaths by breast cancer in 2005-2016 was 23,565.

In multicollinearity analysis among the air pollutants, the $\mathrm{NO}_{2}$ and $\mathrm{O}_{3}$ concentrations were colinear with a correlation coefficient of $-0.862 . \mathrm{O}_{3}$ concentrations were excluded from the multivariable model due to its lesser correlation (0.659) with the breast cancer incidence rate than that of $\mathrm{NO}_{2}$ concentrations (0.774). Both $\mathrm{NO}_{2}$ and $\mathrm{O}_{3}$ concentrations poorly associated with the breast cancer mortality rates $(<0.2$ for both). Other air pollutants, $\mathrm{CO}, \mathrm{SO}_{2}$, and $\mathrm{PM}_{10}$ showed little evidence of collinearity with $<0.7$ correlation coefficients. Among the confounding factors, higher education rate was collinear with population density, parity, unemployment rate, breastfeeding rate, and oral contraceptive usage rate with $>0.7$ correlation coefficients. Among those, only higher education rate was included in the model due to its strongest association with the breast cancer incidence rate $(0.832)$. Altitude, smoking rate, obesity rate, gross regional domestic product (GRDP) per capita, and higher education rate were not significantly collinear among each other, so those five confounding factors were incorporated to the beta regression model in estimating the odds ratio $(\mathrm{OR})$ of $\mathrm{CO}, \mathrm{NO}_{2}, \mathrm{SO}_{2}, \mathrm{PM}_{10}$ concentrations for breast cancer incidence and mortality rates as covariates.

Table 2 shows the OR estimates by single-pollutant and multi-pollutant multivariable linear regression models adjusted for altitude, higher-education rate, smoking rate, obesity rate, and GRDP per capita. In single-pollutant models, all of the four pollutants, $\mathrm{CO}, \mathrm{NO}_{2}, \mathrm{SO}_{2}$, and $\mathrm{PM}_{10}$ were significantly associated with breast cancer incidence. For example, a district with $10 \mathrm{ppb}$ higher $\mathrm{NO}_{2}$ concentration suffered from higher OR of breast cancer incidence by 1.14 (95\% Confidence Interval: 1.12-1.16). In multi-pollutant models, all of the four pollutants remained associated with the breast cancer incidence rate when additionally adjusted with the other three pollutants. On the other hand, air pollutants' concentrations and the breast cancer mortality rates exhibited subtler associations. $\mathrm{CO}, \mathrm{NO}_{2}$, and $\mathrm{SO}_{2}$ showed positive but not significant associations, both in single- and multi-pollutant models. Only PM10 exhibited significant associations with the breast cancer mortality rate both in single- and multi-pollutant models, but with smaller ORs than those with the breast cancer incidence rate.

\section{Discussion}

$\mathrm{NO}_{2}$ and $\mathrm{PM}_{10}$ concentrations were significantly and positively associated with the breast cancer incidence rate in South Korean female population. This result is consistent with previous studies that reported significantly higher risk of breast cancer incidence ${ }^{5,7,9,11}$, and is partly consistent with studies that reported suggestive $6,8,10,12,14,15,27$ or null ${ }^{11,21-23,28}$ associations between air pollutants and breast cancer. Our study adds evidence of a significant positive association to the aforementioned studies. It is also important to note that our finding is based on region-based national census data that encompassed the entire female population of a country $(24,149,865$ in 2010) for more than 10 years, including the complete set of diagnosed breast cancer incidences $(132,811)$ and deaths $(23,565)$ during that period. This region-based national census data could covary out possible confounders, including the data-collection method and any other unknown factors. This adds a new layer of evidence for the association between air pollution and breast cancer incidence rates to the previous studies that had case-control or cohort settings. Differences in the significance of the positive association in our study and 


\begin{tabular}{|c|c|}
\hline Characteristic & $\begin{array}{l}\text { Numbers or median }\left(1^{\text {st }}-3^{\text {rd }}\right. \\
\text { quartile range })\end{array}$ \\
\hline Number of districts & 251 \\
\hline $\begin{array}{l}\text { Age-adjusted breast cancer mortality } \\
\text { rate (per } 100,000)^{\mathrm{a}}\end{array}$ & $6.60(5.65-7.50)$ \\
\hline $\begin{array}{l}\text { Age-adjusted breast cancer incidence } \\
\text { rate (per } 100,000)^{\mathrm{b}}\end{array}$ & $41.6(35.2-46.5)$ \\
\hline Carbon monoxide $(\mathrm{ppb})^{\mathrm{c}}$ & $531(462-597)$ \\
\hline Nitrogen dioxide (ppb) & $19.9(14.1-27.6)$ \\
\hline Sulfate dioxide (ppb) & $4.93(4.04-5.65)$ \\
\hline Ozone (ppb) & $25.0(22.0-28.6)$ \\
\hline $\mathrm{PM}_{10}\left(\mu \mathrm{g} / \mathrm{m}^{3}\right)$ & $49.2(45.6-54.2)$ \\
\hline Altitude (m) & $124(58.9-220)$ \\
\hline Population density $\left(\right.$ per $\mathrm{km}^{2}$ ) & $410(110-6394)$ \\
\hline Higher-education rate ${ }^{\mathrm{d}}(\%)$ & $29.1(16.8-36.9)$ \\
\hline Smoking rate ${ }^{\mathrm{e}}(\%)$ & $25.1(23.4-26.8)$ \\
\hline Obesity rate f $\left.^{\mathrm{f}} \%\right)$ & $22.4(20.9-24.4)$ \\
\hline Parity ${ }^{g}$ & $2.5(2.2-2.7)$ \\
\hline Unemployment rate ${ }^{\mathrm{h}}(\%)$ & $2.7(2.2-3.8)$ \\
\hline Breast feeding rate $(\%)$ & $0.883(0.862-0.898)$ \\
\hline Oral contraceptive usage rate $(\%)$ & $0.131(0.106-0.141)$ \\
\hline GRDP per capitak (million won) & $22.8(16.7-28.8)$ \\
\hline
\end{tabular}

Table 1. Characteristics of the study area. From 2005 to 2016, the female population in all 251 South Korean administrative districts, Si-Gun-Gus, were studied. Korean female population, as of 2010 (in the middle of the study period) was $24,149,865$. ${ }^{a}$ Total number of deaths by breast cancer from 2005-2016 was 23,565. The annual raw mortality rates throughout the study period were adjusted for each district's age distribution to the standard Koran female population in 2010 . ${ }^{b}$ Breast cancer incidence data were surveyed by the Korean government in every 5 years. The number of breast cancer incidence in the nationwide female population in 2004-2008 period was 54,859, and in 2009-2013 period was 77,952. 'Air pollution data in 2004-2016 were accessed via AirKorea database in daily mean concentrations according to the positions of monitoring stations. An interpolation model based on a geographical information system was applied to yield average air pollutant concentration throughout the study period of the corresponding districts. ${ }^{\mathrm{d}}$ Rate of $>15$-year-old women with equal to or higher than a college education in 2010 . ${ }^{\text {Rate }}$ of current female smokers adjusted by the age of the national standard female population in 2010. ${ }^{\text {fRate }}$ of females with BMI $>25$ adjusted by the age of the national

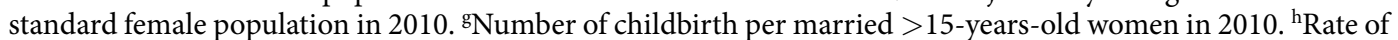

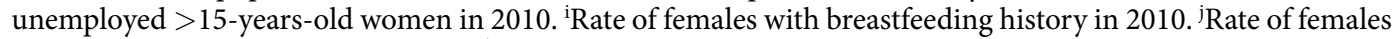
with oral contraceptive usage in 2010. ${ }^{\mathrm{k}}$ Gross Regional Domestic Product per capita in 2011.

aforementioned studies may be due to the relatively severer air pollution in South Korea (Table 1) compared with the air pollution measured in European ${ }^{10,23}$ or North American cohorts ${ }^{6,8,11,14,22,27}$. If so, countries with severe air pollution, such as China or India, may also exhibit significant positive associations that are similar to our result. Differences in ethnic composition, diet, and culture may have also played a role. In addition, subsequent studies will be needed to uncover the underlying physiological mechanisms and pathways in these associations. As previous studies ${ }^{14-16,19}$ suggest, $\mathrm{NO}_{2}$ and $\mathrm{PM}_{10}$ may exert both endocrine-disrupting and carcinogenic properties. Regions with severe air pollution may co-localize with other endocrine-disrupting agents or carcinogens, thereby exhibiting a harmful association with breast cancer incidence.

On the other hand, no significant association was found between air pollution and breast cancer mortality rates except $\mathrm{PM}_{10}$. The breast cancer incidence and mortality rates are positively, but weakly associated in South Korea, with a Pearson's correlation coefficient of 0.150 (p-value: 0.0173 ). This weak association implies that there are some districts with higher mortality rates than expected with their incidence rates. Many of these districts are located in rural areas, supporting an idea that they are underserved by the healthcare system (including late-detection or late-diagnosis) but we did not find significant differences between these low-incidence-high-mortality districts and the other districts. After the breast cancer diagnosis, a patient may have various treatment and management options that considerably affect the mortality rate, and those are hard to parameterize in a census-based study setting. For instance, living in a polluted urban area may lead to a high incidence rate but not to a high mortality rate, by providing better access to healthcare resources than other parts of the country. Similarly, the higher-education rate is positively correlated with the incidence rate, but not with mortality rate. Higher education is usually associated with a Westernized diet pattern, fewer childbirths, prolonged time-to-first pregnancy, and less breastfeeding. These factors contribute to a higher risk of breast cancer incidence. On the other hand, higher education may lower the mortality rate by promoting patients to seek better means to fight the disease. There are studies reporting that different education groups have disparate treatment and mortality patterns in South Korea ${ }^{29}$ and China ${ }^{30}$.

Our breast cancer incidence and mortality statistics are based on a validated national census database, encompassing the whole female population in South Korea. Although this makes our study robust, a limitation also 

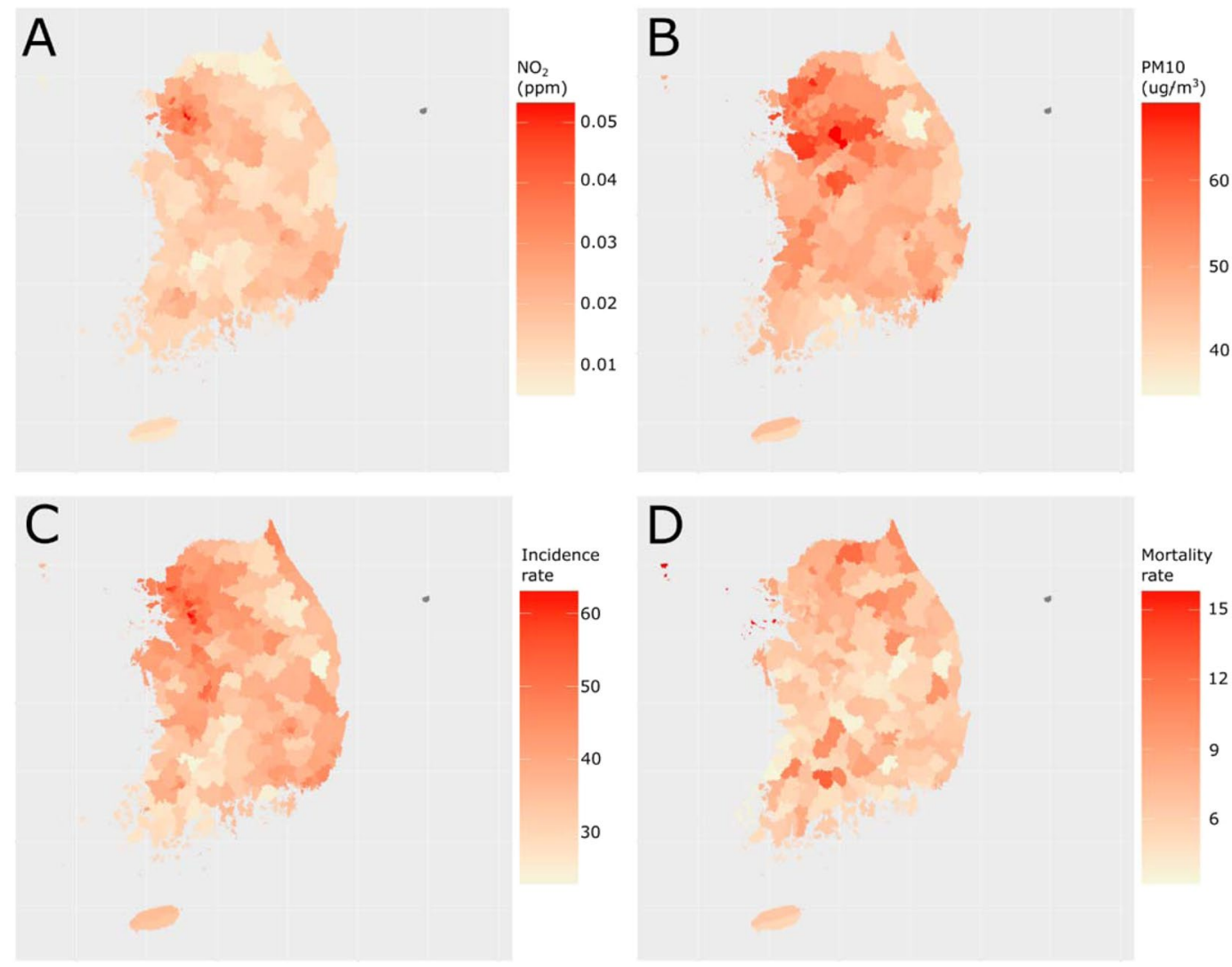

Figure 1. Concentrations of $\mathrm{NO}_{2}$ and $\mathrm{PM}_{10}$, and age-adjusted breast cancer incidence and mortality rates portrayed on the South Korean map. (A) $\mathrm{NO}_{2}$ concentration in average of the study period (2004-2016), (B) $\mathrm{PM}_{10}$ concentration in average of 2004-2016, (C) age-adjusted breast cancer incidence rate in average of 20042013, and (D) age-adjusted breast cancer mortality rate in average of 2005-2016, in South Korea.

\begin{tabular}{|c|c|c|}
\hline & $\begin{array}{l}\text { Breast cancer incidence } \\
\text { rate OR }(95 \% \mathrm{CI})\end{array}$ & $\begin{array}{l}\text { Breast cancer mortality } \\
\text { rate OR }(95 \% \mathrm{CI})\end{array}$ \\
\hline \multicolumn{3}{|l|}{ Single-pollutant } \\
\hline $\mathrm{CO}($ per $100 \mathrm{ppb})$ & $1.08(1.06-1.10)$ & $1.02(0.987-1.05)$ \\
\hline $\mathrm{NO}_{2}($ per $10 \mathrm{ppb})$ & $1.14(1.12-1.16)$ & $1.02(0.983-1.05)$ \\
\hline $\mathrm{SO}_{2}($ per $1 \mathrm{ppb})$ & $1.04(1.02-1.05)$ & $1.02(0.991-1.04)$ \\
\hline $\mathrm{PM}_{10}\left(\right.$ per $\left.10 \mu \mathrm{g} / \mathrm{m}^{3}\right)$ & $1.13(1.09-1.17)$ & $1.05(1.01-1.09)$ \\
\hline \multicolumn{3}{|l|}{ Multi-pollutant } \\
\hline $\mathrm{CO}$ with $\mathrm{NO}_{2}, \mathrm{SO}_{2}$, and $\mathrm{PM}_{10}$ & $1.09(1.07-1.12)$ & $1.02(0.989-1.05)$ \\
\hline $\mathrm{NO}_{2}$ with $\mathrm{CO}, \mathrm{SO}_{2}$, and $\mathrm{PM}_{10}$ & $1.14(1.11-1.16)$ & $1.03(0.985-1.06)$ \\
\hline $\mathrm{SO}_{2}$ with $\mathrm{CO}, \mathrm{NO}_{2}$, and $\mathrm{PM}_{10}$ & $1.04(1.02-1.06)$ & $1.01(0.989-1.03)$ \\
\hline $\mathrm{PM}_{10}$ with $\mathrm{CO}, \mathrm{NO}_{2}$, and $\mathrm{SO}_{2}$ & $1.13(1.08-1.17)$ & $1.04(1.00-1.09)$ \\
\hline
\end{tabular}

Table 2. Odds Ratios (OR) from multivariable beta regression models with air pollutants controlled for altitude, higher-education rate, smoking rate, obesity rate, and GRDP per capita.

arises. Because the unit of analysis was a district, not an individual, some information considered to be important in breast cancer incidence could not be obtained, such as: histologic subtypes, stage at diagnosis, menopausal status, molecular subtypes, mammographic breast density, occupational history, and patient-specific exposure to air pollution. Further research is needed to unveil the interplay of breast cancer, air pollution, and these not-yet-studied risk factors. We did not perform a lag analysis due to the lack of temporal resolution in the breast cancer incidence that had been surveyed every 5 years (in 2004-2008 period and 2009-2013 period, only twice in the study period). Because there was no predefined 'duration of exposure' nor a 'lag-year' value from an exposure to air pollution to lead to a breast cancer incidence or mortality case, the average of daily air pollutant concentrations throughout the study period in each district was considered to represent the level of air pollution. More frequent survey on the breast cancer incidence would enable time series analysis and may lead to richer implications to the field. Another limitation is the lack of migration history data. We contend that migrations 
would not significantly flaw the current study because only approximately $10 \%$ of the population moved between different districts in South Korea between 2003 and $2013^{31,32}$, and the average duration of living in the same district, according to the 2005 Census, was about 7.7 years $^{31,32}$.

\section{Conclusions}

Our study suggests a positive association between air pollution and breast cancer incidence, but less definitively with the mortality rate. This region-based, nationwide, whole-population study adds a new layer of evidence for the association.

\section{Methods}

Ethical approval. Ethical approval was not required because this study was performed using a publicly accessible, national epidemiology database.

Breast cancer incidence and mortality statistics. Korean Statistical Information Service (KOSIS) ${ }^{32}$ is a publicly accessible database that was used to extract the breast cancer incidence and mortality rate, which was classified by the Korean Standard Classification of Disease codes for "breast cancer", C50, and corresponding with the same disease category in the 10th revision of International Statistical Classification of Diseases (ICD-10) and Related Health Problems codes. Mortality statistics were provided from 2005-2016, and incidence statistics were from 2004-2013 by the KOSIS database. There are currently 252 Si-Gun-Gus in South Korea. Si-Gun-Gu is a level in the Korean administrative-area system, similar to the county in the United States. All 252 districts were included in this study, except Ulleung-Gun-a group of islands $130 \mathrm{~km}$ away from the east coast, populated by fewer than 10,000 people. The incidence and mortality rates were age-adjusted per 100,000 by the standard populations as of July $1^{\text {st }}, 2010$ in South Korea. Breast cancer incidence or deaths in the male population were too scarce to be included in the study, so only the female population was analyzed.

Air pollution. Air pollution data throughout the study period and places were acquired from a publicly accessible database. $\mathrm{CO}, \mathrm{SO}_{2}, \mathrm{NO}_{2}, \mathrm{O}_{3}, \mathrm{PM}_{10}$, and $\mathrm{PM}_{2.5}$ concentrations are measured by National Ambient Air Quality Monitoring Information System (NAMIS), and publicly accessible via the AirKorea website. In total, there are 332 measurement stations nationwide. $\mathrm{PM}_{2.5}$ was not assessed in the current study because of shortage in measurement stations in the early study period. The average of each pollutant, per day, for each station was collected.

Although the air pollution data are based on the measurement stations, the population, incidence, and death statistics are based on the Si-Gun-Gu district system, which is not directly matched to each other. To match and integrate the datasets, we obtained the latitudes and longitudes of each air pollution measurement station and administrative authorities office as a representative location for each district. Then we estimated the average air pollutant concentrations throughout the study period for each administrative office by linearly interpolating air pollutant measurements from the surrounding three stations. Python programming language version 2.7 (Python Software Foundation, Beaverton, Oregon, United States) was used in the procedure.

Considering the nature of cancer incidence that depends on long-term, cumulative exposure to putative carcinogens, a clear-cut exposure timing may not be determined. Rather, we summarized the mean ambient pollutant concentrations throughout the whole study period (2004-2016).

Confounding factors. Altitude, population density, higher-education rate, smoking rate, obesity rate, parity, unemployment rate, breastfeeding rate, oral contraceptive usage rate as of the 2010 Census, and gross regional domestic product (GRDP) per capita as of 2011 were accessed for every districts via the KOSIS database and considered as potential confounding factors. The rates are defined as follows: higher education rate (rate of $>15$-year-old women with equal to or higher education than college education in the district), smoking rate (rate of current female smokers adjusted by the age of the national standard female population), obesity rate (rate of females with BMI $>25$ adjusted by the age of the national standard female population), parity (number of childbirth per married $>15$-years-old women), unemployment rate (rate of unemployed $>15$-years-old women), breastfeeding rate (rate of females with breastfeeding history), oral contraceptive usage rate (rate of females with oral contraceptive usage). Parity, unemployment rate, breastfeeding rate, and oral contraceptive usage rate were provided only per 17 provinces, that is coarser than other covariates provided per 252 districts. For parity, unemployment rate, breastfeeding rate, and oral contraceptive usage rate, districts in the same province were attributed with the same estimates.

Statistical analysis. Data are shown as median and interquartile range and the $95 \%$ confidence interval $(95 \% \mathrm{CI})$ where applicable. Multivariable beta regression ${ }^{33,34}$ models for the breast cancer incidence rates and mortality rates were built, and odds ratio (OR) of each air pollutant to the incidence and mortality rates were estimated, adjusting for the confounding factors. To estimate the $95 \%$ confidence intervals for ORs, a basic bootstrap method was applied. To minimize the multicollinearity in the model, variable pairs with Pearson's correlation coefficients higher than 0.7 were identified, and variables of lower correlation with the breast cancer incidence rate and mortality rates were excluded from the model. $\mathrm{R}$ statistics software version 3.6.2 (R Foundation for Statistical Computing, Vienna, Austria) was used in this study.

\section{Data availability}

The data that support the findings of this study are available from public databases: Korean Statistical Information Service, http://kosis.kr/; AirKorea, an air quality information system provided by the Korean Ministry of Environment and the Korean Environment Corporation, http://www.airkorea.or.kr/index; SHAPE file of South Korean map available at National Geographic Information Institute of Korea, http://ngii.go.kr. 
Received: 8 August 2018; Accepted: 9 March 2020;

Published online: 25 March 2020

\section{References}

1. Torre, L. A., Islami, F., Siegel, R. L., Ward, E. M. \& Jemal, A. Global Cancer in Women: Burden and Trend. Cancer Epidem Biomar 26, 444-457, https://doi.org/10.1158/1055-9965.Epi-16-0858 (2017).

2. Jung, K. W. et al. Cancer Statistics in Korea: Incidence, Modality, Survival, and Prevalence in 2014. Cancer Res Treat 49, 292-305, https://doi.org/10.4143/crt.2017.118 (2017)

3. Park, E. H. et al. Basic Facts of Breast Cancer in Korea in 2014:The 10-Year Overall Survival Progress. J Breast Cancer 20, 1-11, https://doi.org/10.4048/jbc.2017.20.1.1 (2017).

4. Lopez-Abente, G. et al. Time trends in municipal distribution patterns of cancer mortality in Spain. Bmc Cancer 14, https://doi. org/10.1186/1471-2407-14-535 (2014).

5. Chen, F. \& Bina, W. F. Correlation of white female breast cancer incidence trends with nitrogen dioxide emission levels and motor vehicle density patterns. Breast Cancer Res Tr 132, 327-333, https://doi.org/10.1007/s10549-011-1861-z (2012).

6. Crouse, D. L., Goldberg, M. S., Ross, N. A., Chen, H. \& Labreche, F. Postmenopausal Breast Cancer is Associated with Exposure to Traffic-Related Air Pollution in Montreal, Canada: A Case-Control Study. Environ Health Persp 118, 1578-1583, https://doi. org/10.1289/ehp.1002221 (2010).

7. Datzmann, T. et al. Outdoor air pollution, green space, and cancer incidence in Saxony: a semi-individual cohort study. Bmc Public Health 18, https://doi.org/10.1186/s12889-018-5615-2 (2018).

8. Hystad, P. et al. Exposure to traffic-related air pollution and the risk of developing breast cancer among women in eight Canadian provinces: A case-control study. Environ Int 74, 240-248, https://doi.org/10.1016/j.envint.2014.09.004 (2015).

9. Wei, Y. D., Davis, J. \& Bina, W. F. Ambient air pollution is associated with the increased incidence of breast cancer in US. Int J Environ Heal R 22, 12-21, https://doi.org/10.1080/09603123.2011.588321 (2012).

10. Andersen, Z. J. et al. Long-Term Exposure to Ambient Air Pollution and Incidence of Postmenopausal Breast Cancer in 15 European Cohorts within the ESCAPE Project. Environ Health Persp 125, https://doi.org/10.1289/Ehp1742 (2017).

11. Reding, K. W. et al. Breast Cancer Risk in Relation to Ambient Air Pollution Exposure at Residences in the Sister Study Cohort. Cancer Epidem Biomar 24, 1907-1909, https://doi.org/10.1158/1055-9965.Epi-15-0787 (2015).

12. Bonner, M. R. et al. Breast cancer risk and exposure in early life to polycyclic aromatic hydrocarbons using total suspended particulates as a proxy measure. Cancer Epidem Biomar 14, 53-60 (2005).

13. Mordukhovich, I. et al. Associations between Polycyclic Aromatic Hydrocarbon-Related Exposures and p53 Mutations in Breast Tumors. Environ Health Persp 118, 511-518, https://doi.org/10.1289/ehp.0901233 (2010).

14. Callahan, C. L. et al. Lifetime exposure to ambient air pollution and methylation of tumor suppressor genes in breast tumors. Environ Res 161, 418-424, https://doi.org/10.1016/j.envres.2017.11.040 (2018).

15. Rodgers, K. M., Udesky, J. O., Rudel, R. A. \& Brody, J. G. Environmental chemicals and breast cancer: An updated review of epidemiological literature informed by biological mechanisms. Environ Res 160, 152-182, https://doi.org/10.1016/j.envres.2017.08.045 (2018).

16. Yaghjyan, L. et al. Association between air pollution and mammographic breast density in the Breast Cancer Surveilance Consortium. Breast Cancer Res 19, https://doi.org/10.1186/s13058-017-0828-3 (2017).

17. Brody, J. G. \& Rudel, R. A. Environmental pollutants and breast cancer. Environ Health Persp 111, 1007-1019, https://doi. org/10.1289/ehp.6310 (2003).

18. Huynh, S. et al. Long-term exposure to air pollution and mammographic density in the Danish Diet, Cancer and Health cohort. Environ Health-Glob 14, https://doi.org/10.1186/s12940-015-0017-8 (2015)

19. Hung, L. J. et al. Traffic Air Pollution and Risk of Death from Breast Cancer in Taiwan: Fine Particulate Matter (PM2.5) as a Proxy Marker. Aerosol Air Qual Res 12, 275-282, https://doi.org/10.4209/aaqr.2011.09.0155 (2012).

20. White, A. J., Bradshaw, P. T. \& Hamra, G. B. Air pollution and Breast Cancer: A Review. Curr Epidemiol Rep 5, 92-100, https://doi. org/10.1007/s40471-018-0143-2 (2018).

21. Goldberg, M. S. et al. The association between the incidence of postmenopausal breast cancer and concentrations at street-level of nitrogen dioxide and ultrafine particles. Environ Res 158, 7-15, https://doi.org/10.1016/j.envres.2017.05.038 (2017).

22. Hart, J. E. et al. Long-term Particulate Matter Exposures during Adulthood and Risk of Breast Cancer Incidence in the Nurses' Health Study II Prospective Cohort. Cancer Epidem Biomar 25, 1274-1276, https://doi.org/10.1158/1055-9965.Epi-16-0246 (2016).

23. Raaschou-Nielsen, O. et al. Air pollution from traffic and cancer incidence: a Danish cohort study. Environ Health-Glob 10, https:// doi.org/10.1186/1476-069x-10-67 (2011).

24. Center, N. C. National Cancer Screening Services, http://www.ncc.re.kr/.

25. Suh, M. et al. Trends in Cancer Screening Rates among Korean Men and Women: Results of the Korean National Cancer Screening Survey, 2004-2013. Cancer Res Treat 48, 1-10, https://doi.org/10.4143/crt.2014.204 (2016).

26. GLOBOCAN 2012, Estimated cancer incidence, mortality and prevalence worldwide in 2012, http://globocan.iarc.fr/Pages/fact_ sheets cancer (2012).

27. Shekarrizfard, M. et al. Investigating the role of transportation models in epidemiologic studies of traffic related air pollution and health effects. Environ Res 140, 282-291, https://doi.org/10.1016/j.envres.2015.04.002 (2015).

28. Hansen, A. B. et al. Long-term exposure to fine particulate matter and incidence of diabetes in the Danish Nurse Cohort. Environ Int 91, 243-250, https://doi.org/10.1016/j.envint.2016.02.036 (2016).

29. Bahk, J., Jang, S. M. \& Jung-Choi, K. Increased breast cancer mortality only in the lower education group: age-period-cohort effect in breast cancer mortality by educational level in South Korea, 1983-2012. Int J Equity Health 16, 56, https://doi.org/10.1186/ s12939-017-0554-6 (2017).

30. Liu, Y. et al. Influence of occupation and education level on breast cancer stage at diagnosis, and treatment options in China: A nationwide, multicenter 10-year epidemiological study. Medicine (Baltimore) 96, e6641, https://doi.org/10.1097/ MD.0000000000006641 (2017).

31. Kim, O. J., Kim, S. Y. \& Kim, H. Association between Long-Term Exposure to Particulate Matter Air Pollution and Mortality in a South Korean National Cohort: Comparison across Different Exposure Assessment Approaches. Int J Env Res Pub He 14, https://doi. org/10.3390/ijerph14101103 (2017).

32. Korea, S. Statistics Korea News, http://kostat.go.kr/portal/eng/news/3/index.board (2019).

33. Ferrari, S. L. P. \& Cribari-Neto, F. Beta regression for modelling rates and proportions. J Appl Stat 31, 799-815, https://doi. org/10.1080/0266476042000214501 (2004).

34. Cribari-Neto, F. \& Zeileis, A. Beta Regression in R. J Stat Softw 34, 1-24 (2010).

\section{Author contributions}

J.H., B.K., and N.K. conceived and designed the study. J.H., H.B. and S.C. helped in the acquisition of data. J.H., S.C. and H.Y. performed the analysis with the supervision of B.K. and N.K. J.H. drafted the article and H.B., S.C., H.Y., B.K., and N.K. revised it critically for important intellectual content. All listed authors contributed to the wording the manuscript and reviewing the final version of the paper. 


\section{Competing interests}

The authors declare no competing interests.

\section{Additional information}

Correspondence and requests for materials should be addressed to B.K. or N.K.

Reprints and permissions information is available at www.nature.com/reprints.

Publisher's note Springer Nature remains neutral with regard to jurisdictional claims in published maps and institutional affiliations.

(c) (i) Open Access This article is licensed under a Creative Commons Attribution 4.0 International License, which permits use, sharing, adaptation, distribution and reproduction in any medium or format, as long as you give appropriate credit to the original author(s) and the source, provide a link to the Creative Commons license, and indicate if changes were made. The images or other third party material in this article are included in the article's Creative Commons license, unless indicated otherwise in a credit line to the material. If material is not included in the article's Creative Commons license and your intended use is not permitted by statutory regulation or exceeds the permitted use, you will need to obtain permission directly from the copyright holder. To view a copy of this license, visit http://creativecommons.org/licenses/by/4.0/.

(c) The Author(s) 2020 